Article

\title{
De novo Assembly, Annotation, and Analysis of Transcriptome Data of the Ladakh Ground Skink Provide Genetic Information on High-Altitude Adaptation
}

\author{
Sylvia Hofmann ${ }^{1,2, * \mathbb{D}}$, Chitra Bahadur Baniya ${ }^{3}$, Matthias Stöck ${ }^{4,5}$ and Lars Podsiadlowski ${ }^{6}$ \\ 1 Centre of Taxonomy and Evolutionary Research, Zoological Research Museum Alexander Koenig, \\ D-53113 Bonn, Germany \\ 2 Department of Conservation Biology, UFZ-Helmholtz-Centre for Environmental Research, \\ D-04318 Leipzig, Germany \\ 3 Central Department of Botany, Tribhuvan University, Kirtipur 44618, Nepal; chitra.baniya@cdb.tu.edu.np \\ 4 Department of Ecophysiology and Aquaculture, Leibniz-Institute of Freshwater Ecology and Inland Fisheries, \\ D-12587 Berlin, Germany; matthias.stoeck@igb-berlin.de \\ 5 Amphibian Research Center, Hiroshima University, Higashihiroshima 739-8526, Japan \\ 6 Centre for Molecular Biodiversity Research, Zoological Research Museum Alexander Koenig, \\ D-53113 Bonn, Germany; 1.podsiadlowski@leibniz-zfmk.de \\ * Correspondence: s.hofmann@leibniz-zfmk.de
}

check for updates

Citation: Hofmann, S.; Baniya, C.B.; Stöck, M.; Podsiadlowski, L. De novo Assembly, Annotation, and Analysis of Transcriptome Data of the Ladakh Ground Skink Provide Genetic Information on High-Altitude Adaptation. Genes 2021, 12, 1423. https://doi.org/10.3390/ genes12091423

Academic Editor: Björn Voß

Received: 10 August 2021

Accepted: 13 September 2021

Published: 16 September 2021

Publisher's Note: MDPI stays neutral with regard to jurisdictional claims in published maps and institutional affiliations.

Copyright: (c) 2021 by the authors. Licensee MDPI, Basel, Switzerland. This article is an open access article distributed under the terms and conditions of the Creative Commons Attribution (CC BY) license (https:// creativecommons.org/licenses/by/ $4.0 /)$.

\begin{abstract}
The Himalayan Arc is recognized as a global biodiversity hotspot. Among its numerous cryptic and undiscovered organisms, this composite high-mountain ecosystem harbors many taxa with adaptations to life in high elevations. However, evolutionary patterns and genomic features have been relatively rarely studied in Himalayan vertebrates. Here, we provide the first well-annotated transcriptome of a Greater Himalayan reptile species, the Ladakh Ground skink Asymblepharus ladacensis (Squamata: Scincidae). Based on tissues from the brain, an embryonic disc, and pooled organ material, using pair-end Illumina NextSeq 500 RNAseq, we assembled 77,000 transcripts, which were annotated using seven functional databases. We tested $\sim 1600$ genes, known to be under positive selection in anurans and reptiles adapted to high elevations, and potentially detected positive selection for 114 of these genes in Asymblepharus. Even though the strength of these results is limited due to the single-animal approach, our transcriptome resource may be valuable data for further studies on squamate reptile evolution in the Himalayas as a hotspot of biodiversity.
\end{abstract}

Keywords: adaptation; evolution; genomic; high elevation; Himalayas; Scincidae

\section{Introduction}

The Himalayan arc represents one of the world's most important faunal and floral hotspots with high species diversity and endemism [1], which result from the Tertiary orogeny of this mountain chain, its complex topography as well as its great climatic heterogeneity and isolation. The genesis of the Tibetan highlands and the Himalayas since the Paleogene, with the Greater Himalayas starting to rise presumably the earliest in the post-Eocene (for a review, see the supplementary in Hofmann et al. [2]), triggered the evolution of unique biodiversity under gradual high-altitude adaptation, as already shown for anurans [3-7]. Besides amphibians, there are also several reptiles that can cope with life at high altitude in those regions, e.g., Thermophis [8], Phrynocephalus [9], and some Laudakia species [10]. Potential constraints to upslope migration of reptiles (and amphibians) to high-elevation environments are the substantial UV-radiation, the thermal extremes, and especially the oxidative stress, referred to as high-altitude hypoxia, which interacts with temperature in a context-dependent manner to influence thermal performance and limits in terrestrial ectotherms [11,12]. Recent advances in high-throughput sequencing technologies have led to a growing number of genomic studies that address the molecular basis of 
high-altitude adaptation, some of them focused also on reptiles [13-15]. However, such data have been scarce in non-model species of the Greater Himalayas (but see [16]). This results from the general understudied biodiversity of this high-mountain range, presuming a relatively large number of cryptic and undiscovered species [17], even among vertebrates. Molecular data from Himalayan organisms can contribute to understanding of the taxonomic and functional diversity spectra across this species-rich, fragile ecosystem. These data resources are even more important because Himalayan biodiversity is threatened at the very core; rapid warming due to climate change, especially at higher elevations, as well as higher rates of forest degradation and deforestation, infrastructural development, trade routes, and hydropower dams are driving species loss at a very alarming speed [18,19]. To allow future studies in evolutionary biology at a genomic level and to generally provide sufficient and relevant data for Himalayan reptiles, in the present study, we have generated a new genomics data set based on RNAseq for a scincid species from the Greater Himalayas. Using these data, we specifically aimed to identify genes known to play roles in adaptation of terrestrial ectothermic vertebrates to high elevations. Since exposure to oxidative stress can particularly affect the physiology during early development [20] and in oxygen-sensitive organs [21,22], such as the nerve system, we focused on embryonic and brain tissue samples.

Our target species is a scincid lizard in the genus Asymblepharus, the Ladakh Ground Skink, A. ladacensis (GÜNTHER, 1864), which is endemic to the western part of the Himalayas. The genus further contains the following species (Figure 1): A. alaicus (ELPATJEVSKY, 1901), A. eremchenkoi PANFILOV, 1999, A. himalayanus (GÜNTHER, 1864), A. mahabharatus EREMCHENKO, SHAH \& PANFILOV, 1998, A. nepalensis EREMCHENKO \& HELFENBERGER, 1998, and A. tragbulensis (ALCOCK, 1898). Another two species, Asymblepharus medogensis JIANG, WU, GUO, LI \& CHE, 2020 and A. nyingchiensis JIANG, WU, WANG, DING \& CHE, 2020, have been described very recently from Mêdog, Nyingchi in SE Tibet, China. According to a large-scale phylogenetic study of squamates [23], the sampled specimen of A. sikimmensis (BLYTH, 1854) is nested within Scincella and was therefore suggested to be transferred to this genus. However, it remains unclear whether this single specimen had been misidentified as A. sikimmensis since originally it was labeled in the museum collection as Scincella potanini (voucher catalogue number CAS:HERP:194923, see http:/ / portal.vertnet.org/o/cas/herp?id=urn-catalog-cas-herp-194923 (accessed on 29 July 2021) [24].

In general, Asymblepharus is a genus with a still poorly known endemic distribution, origin, and evolutionary history. No studies of its population genetic structure and genetic diversity exist to date for any Asymblepharus taxon, and the current taxonomic relationships of its lineages are in flux [23-25]. The three Himalayan species A. himalayanus, A. ladacensis, and $A$. tragbulensis have frequently been assigned to the genus Himalblepharus Eremchenko, 1987. According to literature data ([26] and references therein) and personal observation, they show a remarkably wide vertical distribution from the foothills ( $150 \mathrm{~m}$ a.s.l.) to the high alpine zone and even up to the snow line ( $5500 \mathrm{~m}$ a.s.l.), making them an excellent model to study the genetic basis of adaptations to high altitudes in ectotherms and the evolutionary processes accounting for them.

With this paper, we characterize the first transcriptome data set of a high-altitude reptile species from the Greater Himalayas and report genes known to play roles in adaptation of ectotherms to high elevations of this non-model reptile. Such data provide the necessary sources for future molecular studies in Himalayan reptiles and high-altitude vertebrates. 


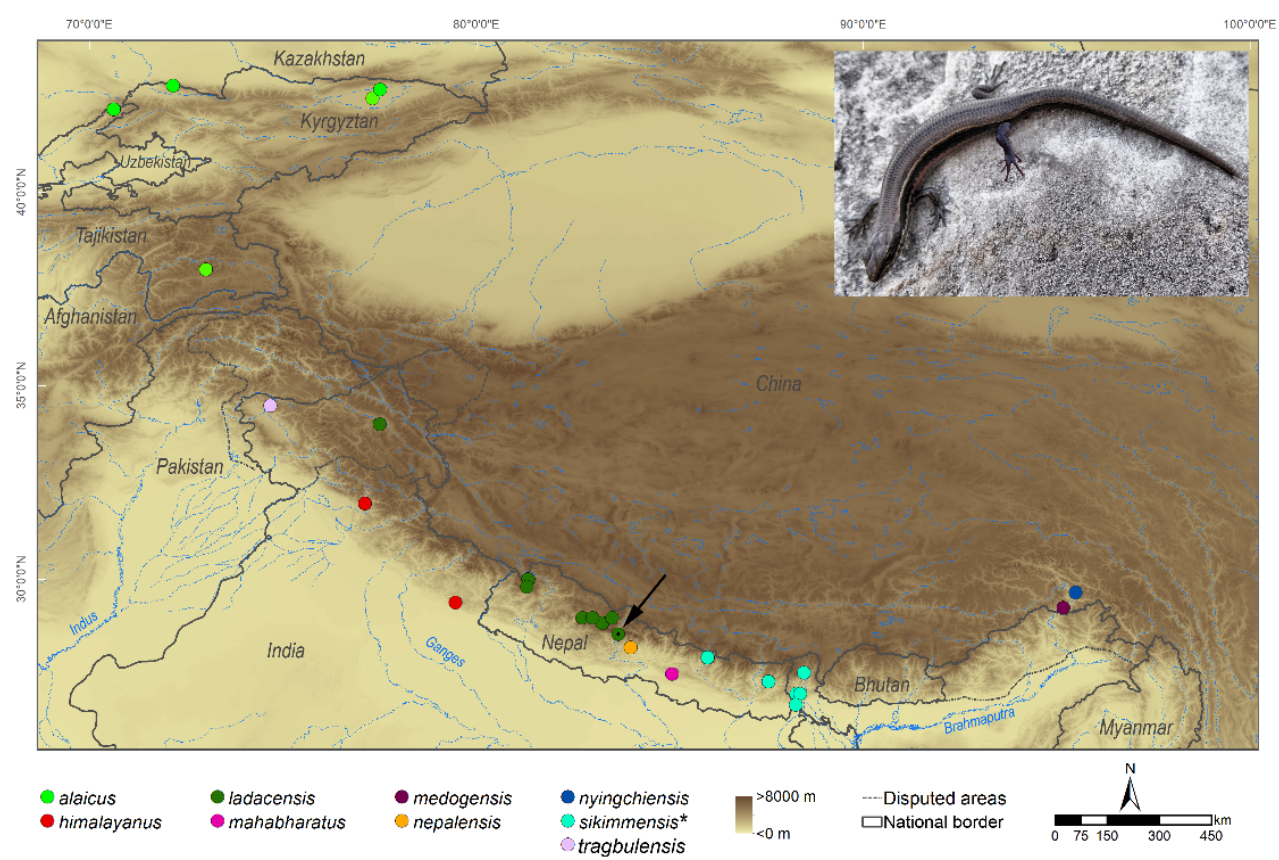

Figure 1. Map of Asymblepharus species based on GBIF (www.gbif.org; accessed on 20 July 2021) records of preserved specimens and georeferenced localities in the taxonomic reptile database (https: / / reptile-database.reptarium.cz/; accessed on 20 July 2021). The location of our RNA sample of the female $A$. ladacensis (photo) is indicated by a green circle with a dot in the middle and an arrow. * Note, according to a large-scale phylogeny of squamates, A. sikimmensis is nested within Scincella; however, it remains unclear whether this single "A. sikimmensis" specimen, on which the sequence data are based, had been taxonomically correctly identified. Therefore, we also show the GBIF records of specimens collected as $A$. sikimmensis. Records of $A$. eremchenkoi in the databases could not be georeferenced due to insufficient information on the collection site. Photo credit: Sylvia Hofmann.

\section{Materials and Methods}

\subsection{Sample Collection and Ethics Statement}

A single gravid female Asymblepharus ladacensis was collected in Central Nepal, in the Dhaulagiri range, west of the Kali Gandaki valley $\left(28.68^{\circ} \mathrm{N}, 83.59^{\circ} \mathrm{E} ; 2714 \mathrm{~m}\right.$ a.s.l.; Figure 1). Samples were collected in accordance with regulations for the protection of terrestrial wild animals under the permits of the Nepal expeditions of the Natural History Museum of Erfurt, Germany $[27,28]$. All treatments were carried out in accordance with approved guidelines and according to the permit as well as the local animal welfare committee's instructions (VNME 17, 15-30). Tissues were transferred into RNAlater (Thermo Fisher), kept at ambient temperature during the time of the fieldwork, and later stored at $-30{ }^{\circ} \mathrm{C}$.

\subsection{RNA Isolation, Library Preparation, and Sequencing}

We followed the same procedure as previously described [16]. In brief, total RNA was isolated from the brain, an embryonic disc, and from pooled tissues (including lung, muscle, and heart) using TRIzol Reagent (Thermo Fisher Scientific, Waltham, MA, USA) according to the supplier's recommendation, in combination with the RNeasy Mini Kit (Qiagen, Hilden, Germany) and adjusted to equal concentrations. RNA quality was assessed by RNA concentration, RIN (RNA Integrity Number) value, 28S/18S and fragment length distribution using an Agilent Bioanalyzer (Agilent Technologies, Inc., Santa Clara, CA, USA).

Complementary DNA (cDNA) library preparation and paired-end sequencing were carried out by BGI (BGI-Hongkong Co., Ltd., Tai Po District, Hong Kong), using Illumina NextSeq500 sequencing system (Illumina, San Diego, CA, USA). The raw reads quality was examined using FastQC v0.11.9 [29]. 


\subsection{Assembly and Assessment of Transcriptome Quality and Completeness}

First, we controlled our data for rRNA quantity using SortMeRNA 4 [30]. The three de novo assemblies were then created following the Oyster River Protocol (ORP; Docker image 2.2.8) best practices [31]. This protocol implements both pre-assembly procedures and a number of different kmer lengths and assemblers, finally merging these assemblies into a single, comprehensive transcriptome. The rationale behind it is that assembling RNAseq reads with different assembly tools increases assembly quality and mapping rate and, in turn, the ability to draw conclusions from that fraction of the sample [31]. Thus, merging the contigs resulting from several assemblers and parameter configurations to combine the advantages of certain assembly mechanisms and to overcome their different disadvantages seems to be the best way to obtain a comprehensive de novo transcriptome assembly $[32,33]$.

Illumina sequencing adapters and nucleotides with quality Phred $\leq 2$ were removed using Trimmomatic v0.36 [34], then the reads were error corrected by Rcorrector version 1.0.2 [35]. These reads were then assembled using Trinity release 2.8.4 [36] with default settings $(k=25)$, two independent runs of SPAdes assembler version 3.11 with kmer lengths of 55 and 75 [37], and the assembler Shannon version 0.0.2 with a kmer length of 75 [38]. The resulting four distinct transcriptome assemblies were then merged to a single, comprehensive transcriptome using Ortho-Fuser [31]. This final transcriptome was evaluated with TransRate version 1.0.3 [39], which is modified for and packaged with the ORP, and with BUSCO (Benchmarking Universal Single-Copy Orthologs) version 4.1.4 [40,41]. Searching the assembly for conserved single-copy orthologs found in orthologous sets of genes constructed from genomes representing eukaryotes (70 species: 255 BUSCOs), vertebrates (67 species: 3354 BUSCOs), and tetrapods (38 species: 5310 BUSCOs).

A detailed quality assessment of the assembly with respect to known genes was further obtained with rnaQUAST version 2.2.0 [42] using the reference genomes of Anolis carolinensis, Gekko japonicus, and Python bivittatus.

\subsection{Functional Annotation}

Transcripts were functionally annotated as previously described [16]. Briefly, sequence homology searches were conducted against seven databases (Gene Onthology, GO; Kyoto Encyclopedia of Genes and Genomes, KEGG; EuKaryotic Orthologous Groups, KOG; InterPro; the non-redundant nucleotide database, NT; the non-redundant protein database, NR; SwissProt). To align our data to KEGG, KOG, NR, and NT and SwissProt, we used Diamond v0.8.31 [43] or the BLASTx [44] algorithm; matched transcripts were filtered by using a cut-off $e$-value of $1 \times 10^{-25}$. Transcripts that aligned to the NR database were transferred to the $\mathrm{GO}$ database with Blast2GO v2.5.0 [45] and assigned into the following three groups: biological process, cellular components, and molecular functions. InterProScan5 v5.11-51.0 tool [46] was used to annotate against the InterPro databases. Blast v2.2.23 was used to search in SwissProt and hmmscan v3.0 [47] for search against Pfam database (for each sample individually). Candidate coding areas within the transcript sequences were predicted by TransDecoder v.3.0.1 [36]. For a coding sequence with multiple open reading frames (ORF), the longest one was selected. We also used the getorf program of the EMBOSS v6.5.70 package [48] to find the ORF of each transcript and mapped them to the Animal Transcription Factor DataBase (AnimalTFDB2.0). The threshold of transcript lengths used for annotation and downstream analyses was $\geq 200 \mathrm{bp}$.

\subsection{Positively Selected Genes Related to Mechanisms of High-Altitude Adaptation}

We selected transcripts of genes reported to exhibit molecular adaptation to high elevations in lizards and anurans as provided in the literature $[7,15]$. This comprised a total of 143 genes identified to be under positive selection (PSG) in high-elevational lineages of lizards (Phrynocephalus vlangalii) [15]. We included further 1481 PSGs of these lizards (P. erythrurus, P. putjatia, P. vlangalii) and of dicroglossid frogs (Nanorana, Quasipaa) [7], genes that were identified across an elevational gradient $(\sim 1000 \mathrm{~m}$ to $4500 \mathrm{~m})$. These additional, individual genes were grouped according to the phylogenetic tree branches 
across the elevational gradient as presented in Sun et al. (2018) [7]: PSGs attributed to branches that represent (i) lowland species ( 1000 m), (ii) species distributed in colline zones up to about $2000 \mathrm{~m}$, (iii) submontane and montane species (2000 and $3500 \mathrm{~m}$ ), and (iv) subalpine and alpine species (>3500 and $4500 \mathrm{~m}$ ). Given the vertical distribution of Asymblepharus ladacensis in the Himalayas between $2500 \mathrm{~m}$ and $4500 \mathrm{~m}$ [49], we expected to find primarily genes under positive selection reported as PSGs for the submontane and montane, as well as the subalpine and alpine species.

To identify scincid orthologs to the genes under positive selection (high-altitude adaptations) in reptiles and amphibians, we used the corresponding coding sequences from Anolis carolinensis (AnoCar2.0, gene build from ensemble 104.2; we used Anolis gene numbers that were mentioned in the publications cited in the last paragraph) as a reference for blast searches. We performed blast searches with the newly sequenced and assembled transcriptome of $A$. ladacensis, as well as with publicly available transcriptome data from the following scincid lizards: Scincella lateralis (NCBI-SRA SRR629642), Lampropholis guichenoti (NCBI-SRA SRR4293354), Lepidothyris fernandi (NCBI-SRA SRR10360868), and Pseudemoia entrecasteauxii (NCBI-SRA SRR3099521). Only the best reciprocal hit between Anolis and each scincid species (and only if the $e$-value was below $10^{-25}$ ) were used for subsequent analyses.

Alignments of orthologs to the Anolis reference were done with mafft v.7.455 [50] making use of the "adjustdirection" and "keeplength" options to get alignments that are in the same direction and keep reading frames intact. Alignments were inspected for good representation of all species under study. When one or more species had substantially shorter, incomplete contigs as best reciprocal hits, we omitted those from the alignment. A phylogenetic tree for each alignment was produced using FastTree v. 2.1.10 [51] with default settings, except for the nucleotide option.

Alignments and trees were analyzed with the HyPhy (Hypothesis Testing using Phylogenies) package v. 2.5 [52,53] using the following methods (for details see [54]): (i) The BUSTED (Branch-Site Unrestricted Statistical Test for Episodic Diversification) [55] model, to test whether a given gene has been subject to positive, diversifying selection at any site, at any time (we tested all lineages for positive selection); (ii) FUBAR (Fast, Unconstrained Bayesian AppRoximation) [56], a Bayesian approach to infer which site(s) in a gene are subject to pervasive, i.e., consistently across the entire phylogeny, diversifying selection (we considered a posterior probability of at least 0.90 as significant); and (iii) the branch-site model aBSREL (adaptive Branch-Site Random Effects Likelihood) [57,58], to test whether codon sites and individual branches are subject to positive selection across the phylogeny. The threshold for significance in BUSTED and aBSREL was set at a $p$-value lower than 0.05 .

GO term and metabolic pathway enrichment analysis was done using pantherdb (pantherdb.org; accessed on 2 August 2021, [59]), using the genome of Anolis carolinensis as reference.

\subsection{Data Availability}

Data generated in this study are publicly available from the NCBI GenBank database under the Bioproject ID PRJNA750278, BioSamples SAMN20458631, SAMN20458632, and SAMN20458631. All sequence data were deposited in the NCBI Sequence Read Archive (SRA, http: / / www.ncbi.nlm.nih.gov / Traces/sra/; accessed on 2 August 2021) under the accession numbers SRR15283177, SRR15283178, and SRR15283179'; assembled sequences were transmitted to NCBI Transcriptome Shotgun Assembly Sequence Database (TSA, http:/ / www.ncbi.nlm.nih.gov / genbank/tsa; accessed on 2 August 2021).

\section{Results}

\subsection{Sequencing and Transcriptome Assembly}

All RNA was reasonably high quality; A260/280 ratios ranged between 1.81 (brain), 1.76 (embryonic disc), and 2.09 (pooled tissues); RIN values were between 7.90, 8.20, and 
9.10, respectively. RNA-seq libraries of the two tissues yielded a total of 74.78, 73.56, and 64.20 million raw sequence reads (Table 1). Pre-processing of reads via read trimming and read error correction removed approximately $2-4 \%$ of the raw data, resulting in $73.14,71.89$, and 61.40 million clean reads for the brain, embryonic disc, and pooled tissues (Table 1). GC content of these clean reads was $48 \%$.

Table 1. Summary of sequencing data used to obtain the de novo transcriptome assemblies of Asymblepharus ladacensis based on paired-end Illumina sequencing. Final assemblies based on four unique assemblies per sample generated by ORP using different assemblers and k-mers.

\begin{tabular}{cccc}
\hline & Brain Tissue & Embryonic Disc Tissue & Pooled Tissue \\
\hline Number of paired-end raw reads & $74,780,628$ & $73,557,120$ & $64,195,486$ \\
Number of cleaned reads & $73,139,294$ & $71,887,892$ & $61,397,610$ \\
Number of base pairs in final assembly & $102,605,079$ & $98,917,807$ & $47,613,446$ \\
Number of transcripts in final assembly & 151,718 & 105,133 & 66,696 \\
Average transcript length (bp) & 676 & 940 & 712 \\
Minimum transcript length (bp) & 131 & 131 & 131 \\
Maximum transcript length (bp) & 17,543 & 18,168 & 15,866 \\
N50 & 1215 & 2052 & 1194 \\
N90 & 257 & 311 & 278 \\
GC\% content of the final ORP assembly & 0.48 & 0.48 & 0.48 \\
\hline
\end{tabular}

The final de novo assemblies generated from ORP resulted in 151,718 (brain), 105,133 (embryonic disc), and 66,696 (pooled tissues) transcripts with a total length of $\sim 102.61$, $\sim 98.92$, and $\sim 47.61$ million bp, respectively. Transcripts had an average length of $676 \mathrm{bp}$ (brain), 940 bp (embryonic disc), and 712 bp (pooled tissues), and an N50 of 1215 bp, 2052 bp, and 1194 bp (Table 1, Supplementary Table S1 and Figure S1). A total of 48,884 (32.22\%; brain), 44,358 (42.19\%; embryonic disc), and 25,772 (38.64\%; pooled tissues) transcripts were longer than 500 bp (Supplementary Table S2).

\subsection{Assembly Completeness}

TransRate's optimal assembly score $(\min 0.0, \max 1.0)$ is considered to be a good parameter of the quality of an assembly [32]; it captures the confidence and completeness of the assembly. The TransRate scores of our final assemblies were high, ranging between 0.44 (optimized score 0.49) for the brain sample, 0.45 (optimized score 0.57 ) for the embryonic disc sample, and 0.44 (optimized score 0.52) for the pooled tissues. A transRate score $>0.22$ is generally thought to be acceptable [31,39]. More than $90 \%$ of the reads were used to assemble the transcriptomes, and $87 \%$ (brain, pooled tissues), as well as $90 \%$ (embryonic disc) of the fragments, were considered as good mappings, while only $1.6 \%$ (brain), 3.7\% (embryonic disc), and 2.7\% (pooled tissues) of assembled contigs had no coverage (Supplementary Table S1).

The assessment of completeness of our assemblies by the BUSCO pipeline resulted in a moderate to high percentage of complete eukaryotic orthologues (from 69.8 to $98.0 \%$ of 255 BUSCOs) but also a significantly higher percentage of putative paralogues; in the vertebrate (3354 BUSCOs) and tetrapod (5310 BUSCOs) databases, more than half of the markers were recovered completely in the brain and embryonic tissue (Table 2). The fraction of missing BUSCOs ranged between $0.8 \%$ (Eukaryota; embryonic disc) and $54.9 \%$ (Tetrapoda; pooled tissues). These BUSCO values are comparable to recent de novo transcriptome studies in many vertebrates [60-62]. BUSCO recovery rate tends to be highest when full organism and/or multiple developmental stages were used to generate the transcriptomes, compared to those assembled from specific organs or tissues [63]. 
Table 2. Benchmarking Universal Single-Copy Orthologs (BUSCO) results based on the eukaryotic (EU, eukaryota_odb10; 255 BUSCOs), vertebrates (VB, vertebrata_odb10; 3354 BUSCOs), and tetrapod databases (TP, tetrapoda_odb10, 5310 BUSCOs) searched. BUSCO searches for completed, single-copy, duplicated, fragmented, and missing orthologs within given genomes.

\begin{tabular}{cccccccccc}
\hline BUSCO Statistics & \multicolumn{3}{c}{ Brain } & \multicolumn{3}{c}{ Embryonic Disc } & \multicolumn{2}{c}{ Pooled Tissues } \\
\hline & EU & VB & TP & EU & VB & TP & EU & VB & TP \\
\hline \multirow{2}{*}{ Complete } & $220 / 255$ & $2052 / 3354$ & $2696 / 5310$ & $250 / 255$ & $2743 / 3354$ & $3778 / 5310$ & $178 / 255$ & $1405 / 3354$ & $1750 / 5310$ \\
& $(86.3 \%)$ & $(61.1 \%)$ & $(50.8 \%)$ & $(98.0 \%)$ & $(81.8 \%)$ & $(71.1 \%)$ & $(69.9 \%)$ & $(41.9 \%)$ & $(33.0 \%)$ \\
Single-copy & $189 / 255$ & $1759 / 3354$ & $2305 / 5310$ & $185 / 255$ & $1871 / 3354$ & $2555 / 5310$ & $148 / 255$ & $1150 / 3354$ & $1421 / 5310$ \\
& $(74.1 \%)$ & $(52.4 \%)$ & $(43.4 \%)$ & $(72.5 \%)$ & $(55.8 \%)$ & $(48.1 \%)$ & $(58.0 \%)$ & $(34.3 \%)$ & $(26.8 \%)$ \\
Duplicated & $31 / 255$ & $293 / 3354$ & $391 / 5310$ & $65 / 255$ & $872 / 3354$ & $1223 / 5310$ & $30 / 255$ & $255 / 3354$ & $329 / 5310$ \\
& $(12.2 \%)$ & $(8.7 \%)$ & $(7.4 \%)$ & $(25.5 \%)$ & $(26.0 \%)$ & $(23.0 \%)$ & $(11.8 \%)$ & $(7.6 \%)$ & $(6.2 \%)$ \\
Fragmented & $23 / 255$ & $589 / 3354$ & $709 / 5310$ & $3 / 255$ & $221 / 3354$ & $323 / 5310$ & $47 / 255$ & $654 / 3354$ & $645 / 5310$ \\
& $(9.0 \%)$ & $(17.6 \%)$ & $(13.4 \%)$ & $(1.2 \%)$ & $(6.6 \%)$ & $(6.1 \%)$ & $(18.4 \%)$ & $(19.5 \%)$ & $(12.1 \%)$ \\
Missing & $12 / 255$ & $713 / 3354$ & $1905 / 5310$ & $2 / 255$ & $390 / 3354$ & $1209 / 5310$ & $30 / 255$ & $1295 / 3354$ & $2915 / 5310$ \\
& $(4.7 \%)$ & $(21.3 \%)$ & $(35.8 \%)$ & $(0.8 \%)$ & $(11.6 \%)$ & $(22.8 \%)$ & $(11.8 \%)$ & $(38.6 \%)$ & $(54.9 \%)$ \\
\hline
\end{tabular}

Coverage of specific gene databases (Anolis carolinensis, Gekko japonicus, Python bivittatus) ranged between 7\% and 29\%, being highest for the Gekko reference genome (Supplementary Table S2). Up to 40,000 transcripts (22-39\%) could be aligned to one of the three databases. The duplication ratio varied between 1.3 and 1.5 and was in the range reported for vertebrate transcriptomes [32,64]. Although the proportion of misassembled contigs was low $(<2 \%)$, the assemblies showed only a small number of $95 \%$-assembled genes and isoforms (Supplementary Table S2). We assume that this might reflect biological novelty in the study species rather than fragmentation of the assemblies [41]. For example, the low proportion of completeness against the three reptile gene databases contrasts with a $>40 \%$ completeness score for the vertebrate gene set and could be the result of an overrepresentation of gene sets from more intensively studied lineages [65].

Alternatively, suboptimal sample quality and a resulting higher proportion of fragmented genes due to potential RNA degradation could be a reason for the relatively low number of assembled genes and lower Eukaryota BUSCO scores, especially in the pooled tissues sample.

\subsection{Functional Annotation}

Annotation of the complete set of transcriptomes from all three samples resulted in $39,975(51.94 \%)$ transcripts annotated in at least one of the seven databases used for functional annotation; 7292 sequences generated hits in all of these databases (Table 3). Approximately $70 \%$ of the top hits matched to genes from Gekko japonicus (7716; 23.07\%), Pogona vitticeps (7239; 21.65\%), Anolis carolinensis (5399; 16.14\%), and Python bivittatus (3176; $9.5 \%)$, Figure 2.

Table 3. Number (N) of transcripts identified in Asymblepharus ladacensis that are shared (=Intersection) and unique among seven annotation database resources. GO-Gene Onthology; InterProintegrative protein signature database; KEGG—Kyoto Encyclopedia of Genes and Genomes; KOGEuKaryotic Orthologous Groups; NR—non-redundant protein database; NT—non-redundant nucleotide database; SwissProt-Swiss Protein Sequence Database.

\begin{tabular}{ccccccccccc}
\hline & Total & NR & NT & SwissProt & KEGG & KOG & InterPro & GO & Intersection & Overall \\
\hline $\mathrm{N}$ & 76,968 & 33,444 & 34,114 & 30,994 & 28,961 & 26,608 & 27,013 & 11,010 & 7292 & 39,975 \\
\hline$\%$ & 100 & 43.45 & 44.32 & 40.27 & 37.63 & 34.57 & 35.10 & 14.30 & 9.47 & 51.94 \\
\hline
\end{tabular}


a)

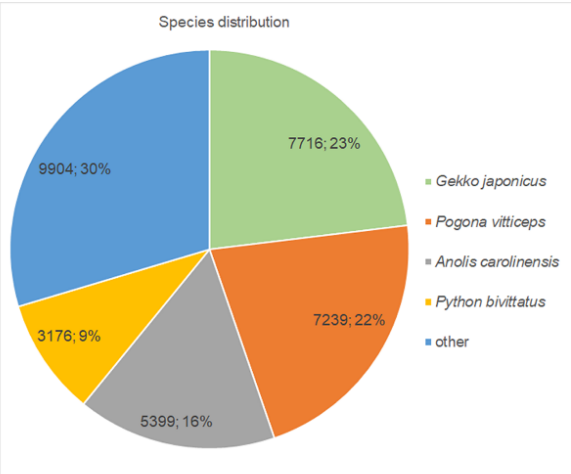

c)

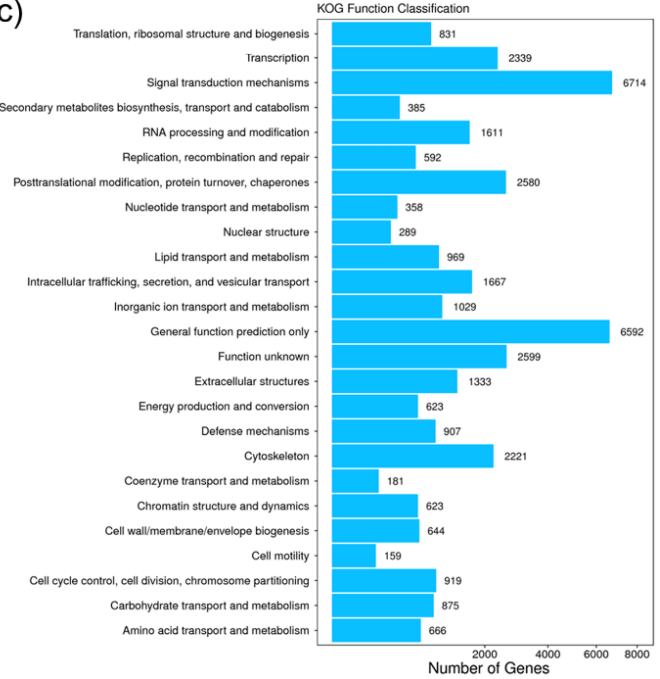

b)

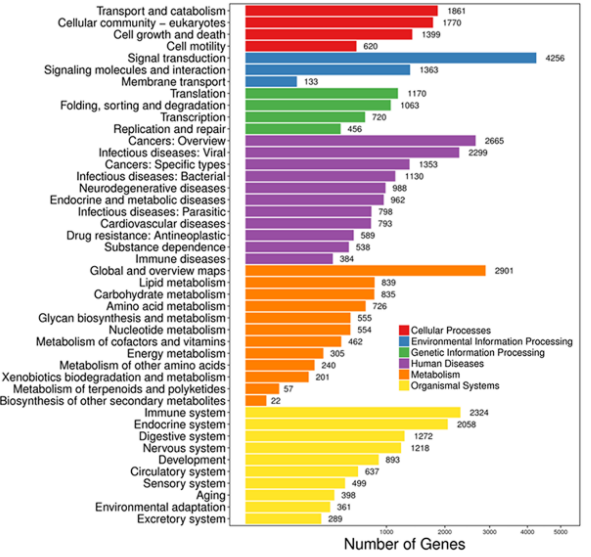

d)

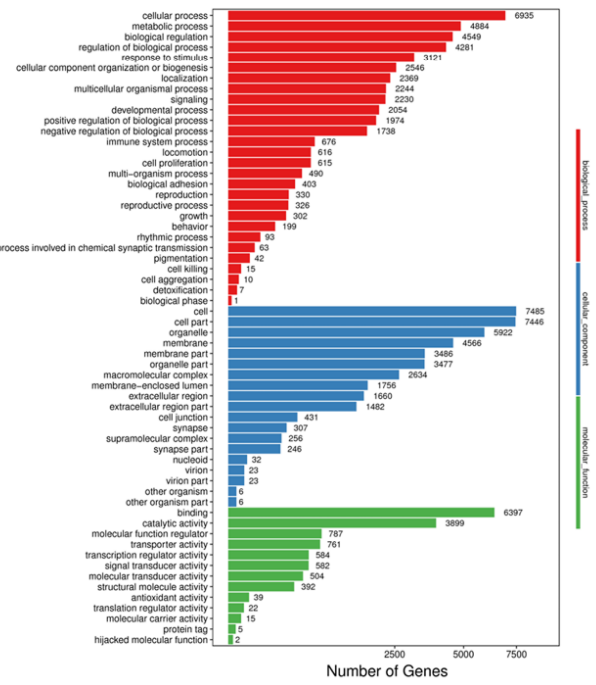

Figure 2. Annotation of the Asymblepharus ladacensis transcriptome. (a) Species distribution of the top BLASTx hit performed against NR database; (b) GO (Gene Onthology) assignments as predicted by Blast2GO; (c) functional distribution of KOG (EuKaryotic Orthologous Groups) annotation and (d) KEGG (Kyoto Encyclopedia of Genes and Genomes) classifications of assembled transcripts.

In terms of the biological process ontology (GO database categories), the most common categories were cellular processes (6935), metabolic processes (4884), and biological regulation (4549). The most frequent classifications for the cellular component ontology were cellular (7485), cell compartments (7446), and organelles (5922). Regarding the molecular function, major categories involved binding (6397), catalytic activity (3899), and molecular function regulator (787) (Figure 2). The KOG functional classification revealed genes of signal transduction mechanisms (6714), general function (6592), unknown function (2599), posttranslational modification (2580), and transcription (2339) as top five categories (Figure 2).

We found 44,956 transcripts in the KEGG database that aligned to entries associated with pathways of cellular processes (5650), environmental information processing (5752), genetic information processing (3409), human diseases (12,499), metabolism (7697), and organismal systems (9949). Predominantly, the genes were enriched in "signal transduction" (4256), followed by "global and overview maps" (2901), "cancers: overview" (2665), "immune system" (2324), and "infectious diseases: viral" (2299) categories (Figure 2).

\subsection{Positive Selection}

Among the 143 PSGs previously reported for the high-elevation lineage of the toadheaded agama Phrynocephalus vlangalii [15], we found ten genes to be likewise under positive selection in Asymblepharus based on all three tests that we performed. Two of these 
genes (IL1RAP, GRK6) were specific to the Asymblepharus branch of the gene tree (Table 4 and Supplementary Table S3).

Table 4. Summary of the positive selection analysis for high-altitude candidate genes of a toad-headed agama (Phrynocephalus vlangalii) [15] tested likewise positive in Asymblepharus (A) using BUSTED (B); $p$-value > 0.05) [55], FUBAR (FB; number of sites under positive selection) [56] and aBSREL $(\mathrm{aB})[57,58]$ methods. PSGs are represented by the last six digits of the anole lizard's (Anolis carolinensis) ENSEMBL gene and transcript identifiers (starting with ENSACAG00000, or ENSACAT00000, respectively).

\begin{tabular}{|c|c|c|c|c|c|c|c|}
\hline GeneID & Gene & $p$-Value [15] & Gene Description & Transcript & B & FB & $\mathrm{aB}$ \\
\hline 000773 & IL1RAP & $3.58 \times 10^{-2}$ & Interleukin 1 receptor accessory protein & 000813 & $<0.00 \times 10^{-5}$ & 2 & A. \\
\hline 000907 & MICU1 & $1.79 \times 10^{-2}$ & Mitochondrial calcium uptake 1 & 000909 & $1.30 \times 10^{-3}$ & 1 & yes \\
\hline 001142 & TARBP1 & $1.39 \times 10^{-6}$ & TAR RNA binding protein 1 & 001104 & $<0.00 \times 10^{-5}$ & 1 & yes \\
\hline 002254 & MIA3 & $1.83 \times 10^{-2}$ & $\begin{array}{c}\text { Melanoma inhibitory activity family } \\
\text { member } 3\end{array}$ & 002276 & $1.93 \times 10^{-2}$ & 1 & yes \\
\hline 002549 & RPS2 & $1.99 \times 10^{-2}$ & Ribosomal protein S2 & 002541 & $5.00 \times 10^{-4}$ & 2 & yes \\
\hline 002995 & RNF10 & $4.38 \times 10^{-2}$ & Ring finger protein 10 & 003046 & $2.63 \times 10^{-2}$ & 5 & yes \\
\hline 003987 & NUP107 & $1.54 \times 10^{-4}$ & Nucleoporin $107 \mathrm{kDa}$ & 004158 & $<0.00 \times 10^{-5}$ & 1 & yes \\
\hline 006133 & GRK6 & $1.07 \times 10^{-2}$ & G protein-coupled receptor kinase 6 & 006252 & $1.16 \times 10^{-2}$ & 2 & A. \\
\hline 007074 & SMC4 & $1.56 \times 10^{-3}$ & $\begin{array}{l}\text { Structural maintenance of } \\
\text { chromosomes } 4\end{array}$ & 007191 & $1.00 \times 10^{-4}$ & 1 & yes \\
\hline 015860 & SH3RF1 & $4.55 \times 10^{-3}$ & $\mathrm{SH} 3$ domain containing ring finger 1 & 015968 & $8.90 \times 10^{-3}$ & 1 & yes \\
\hline
\end{tabular}

Out of the 410 transcripts reported to be under positive selection in lowland frog and lizard species [7], 321 could be identified in Asymblepharus. Of these, 23 (7.2\%) transcripts were found to be under positive selection in the Ladakh Ground Skink in all three tests (Table 5). Similarly, a total of 32 (7.1\% of 449 transcripts) PSGs of colline, 24 (7.6\% of 314 transcripts) of submontane and montane, and 24 (6.9\% of 350 transcripts) of subalpine and alpine frog and lizard species were tested to be under positive selection in Asymblepharus. Moreover, out of the 32 parallel PSGs that were identified in both high-elevation frog and lizard species [7], one gene (PGS1) showed positive selection in the Ladakh Ground Skink (Table 5). Analyzing these genes under positive selection for GO terms and pathways reveals an overrepresentation of genes involved in the following processes: low-density lipoprotein receptors and catabolic processes; mitochondrial citrate transmembrane transport; glycolysis and fructose/galactose metabolism; nucleoside phosphate binding; p53 pathway feedback loop (involved in DNA repair), platelet-derived growth (PDGF) factor binding (involved in blood-vessel formation).

Table 5. Summary of the positive selection analysis for candidate genes of lineages of dicroglossid frogs and toad-headed agamas [7] identified across an elevational gradient, tested likewise positive in Asymblepharus (A) using BUSTED (B); $p$-value > 0.05) [55], FUBAR (FB; number of sites under positive selection) [56] and aBSREL (aB, number of branches with positive selection) $[57,58]$ methods. Ensembl gene and transcript identifier (ENSACAG00000, ENSACAT00000) refers to Anolis carolinensis.

\begin{tabular}{|c|c|c|c|c|c|c|}
\hline \multicolumn{2}{|c|}{ Lowland } & \multirow{2}{*}{ Gene Description } & \multirow{2}{*}{ Transcript } & \multirow{2}{*}{ B } & \multirow{2}{*}{ FB } & \multirow{2}{*}{$\mathbf{a B}$} \\
\hline GeneID & Gene & & & & & \\
\hline 000146 & PCSK9 & Proprotein convertase subtilisin/kexin type 9 & 000163 & $4.40 \times 10^{-3}$ & 1 & 2 \\
\hline 000201 & NPC1 & NPC intracellular cholesterol transporter 1 & 000261 & $5.10 \times 10^{-3}$ & 2 & 1 \\
\hline 000264 & LAMP1 & Lysosomal associated membrane protein 1 & 000247 & $2.90 \times 10^{-3}$ & 8 & 2 \\
\hline 000531 & SEPT12 & Septin 12 & 000602 & $1.29 \times 10^{-2}$ & 1 & 1 \\
\hline 000768 & SYK & Spleen associated tyrosine kinase & 000802 & $<0.00 \times 10^{-5}$ & 1 & 3 \\
\hline 000798 & WBP4 & WW domain binding protein 4 & 000804 & $2.00 \times 10^{-2}$ & 3 & 1 \\
\hline 000955 & QSOX1 & Quiescin sulfhydryl oxidase 1 & 000962 & $9.20 \times 10^{-3}$ & 3 & 1 \\
\hline 001070 & CADM1 & Cell adhesion molecule 1 & 001188 & $1.00 \times 10^{-4}$ & 1 & 1 \\
\hline 002270 & KANK1 & KN motif and ankyrin repeat domains 1 & 002294 & $8.00 \times 10^{-4}$ & 2 & 2 \\
\hline 003015 & VLDLR & Very low-density lipoprotein receptor & 003096 & $1.66 \times 10^{-2}$ & 3 & 1 \\
\hline
\end{tabular}


Table 5. Cont.

\begin{tabular}{|c|c|c|c|c|c|c|}
\hline \multicolumn{2}{|c|}{ Lowland } & \multirow{2}{*}{ Gene Description } & \multirow{2}{*}{ Transcript } & \multirow[b]{2}{*}{ B } & \multirow[b]{2}{*}{ FB } & \multirow[b]{2}{*}{$\mathbf{a B}$} \\
\hline GeneID & Gene & & & & & \\
\hline 003460 & ANKRD12 & Ankyrin repeat domain 12 & 003484 & $1.80 \times 10^{-3}$ & 1 & 1 \\
\hline 003908 & MDM1 & Mdm1 nuclear protein & 003923 & $2.30 \times 10^{-3}$ & 2 & 2 \\
\hline 005884 & CCDC66 & Coiled-coil domain containing 66 & 025744 & $<0.00 \times 10^{-5}$ & 1 & 1 \\
\hline 006279 & GLYR1 & Glyoxylate reductase 1 homolog & 006325 & $<0.00 \times 10^{-5}$ & 1 & 3 \\
\hline 007694 & ACOX1 & Acyl-CoA oxidase 1 & 007823 & $<0.00 \times 10^{-5}$ & 8 & 1 \\
\hline 008005 & PHACTR2 & Phosphatase and actin regulator 2 & 008047 & $4.30 \times 10^{-3}$ & 5 & 1 \\
\hline 008420 & VTA1 & Vesicle trafficking 1 & 008463 & $3.36 \times 10^{-2}$ & 1 & 1 \\
\hline 009938 & & & 010074 & $<0.00 \times 10^{-5}$ & 6 & 3 \\
\hline 013301 & COL1A2 & Collagen type I $\alpha 2$ chain & 013614 & $1.10 \times 10^{-3}$ & 17 & 3 \\
\hline 013917 & MSH2 & MutS homolog 2 & 014076 & $1.11 \times 10^{-2}$ & 1 & 1 \\
\hline 013984 & LRRCC1 & $\begin{array}{l}\text { Leucine-rich repeat and coiled-coil centrosomal } \\
\text { protein } 1\end{array}$ & 014100 & $2.50 \times 10^{-2}$ & 1 & 2 \\
\hline 016683 & TENT2 & Terminal nucleotidyltransferase 2 & 016777 & $<0.00 \times 10^{-5}$ & 2 & 2 \\
\hline 017936 & ATP6V0A1 & ATPase $\mathrm{H}+$ transporting V0 subunit a1 & 018008 & $3.50 \times 10^{-3}$ & 1 & 1 \\
\hline \multicolumn{7}{|c|}{ Up to $2000 \mathrm{~m}$} \\
\hline Gene ID & Gene & Gene description & Transcript & B & FB & $\mathrm{aB}$ \\
\hline 000608 & FBXL3 & F-box and leucine-rich repeat protein 3 & 000548 & $3.47 \times 10^{-2}$ & 2 & 1 \\
\hline 000768 & SYK & Spleen associated tyrosine kinas & 000802 & $<0.00 \times 10^{0}$ & 1 & 3 \\
\hline 000837 & KATNB1 & Katanin p80 (WD repeat containing) subunit B 1 & 000896 & $4.96 \times 10^{-2}$ & 1 & 1 \\
\hline 000955 & QSOX1 & Quiescin sulfhydryl oxidase 1 & 000962 & $8.90 \times 10^{-3}$ & 3 & 1 \\
\hline 002090 & KIAA0232 & KIAA0232 & 002069 & $<0.00 \times 10^{0}$ & 5 & 2 \\
\hline 002091 & RANBP2 & RAN binding protein 2 & 002100 & $7.00 \times 10^{-3}$ & 2 & 1 \\
\hline 002556 & SLC25A1 & Solute carrier family 25 member 1 & 002543 & $5.00 \times 10^{-3}$ & 2 & 1 \\
\hline 002948 & RSPH1 & Radial spoke head component 1 & 002963 & $1.59 \times 10^{-2}$ & 2 & 1 \\
\hline 003975 & TOGARAM1 & TOG array regulator of axonemal microtubules 1 & 004004 & $<0.00 \times 10^{-5}$ & 1 & 3 \\
\hline 003987 & NUP107 & Nucleoporin 107 & 004158 & $<0.00 \times 10^{-5}$ & 1 & 2 \\
\hline 004938 & RARS1 & Arginyl-tRNA synthetase 1 & 005003 & $<0.00 \times 10^{-5}$ & 3 & 2 \\
\hline 005569 & CCT4 & Chaperonin containing TCP1 subunit 4 & 005683 & $2.00 \times 10^{-4}$ & 2 & 1 \\
\hline 006189 & PARP1 & Poly(ADP-ribose) polymerase 1 & 006356 & $4.11 \times 10^{-2}$ & 4 & 1 \\
\hline 006926 & CTNND1 & Catenin delta 1 & 007006 & $3.00 \times 10^{-4}$ & 1 & 1 \\
\hline 007100 & ZNF277 & Zinc finger protein 277 & 007173 & $1.17 \times 10^{-2}$ & 3 & 3 \\
\hline 007489 & PRDX4 & Peroxiredoxin 4 & 007498 & $2.20 \times 10^{-3}$ & 1 & 1 \\
\hline 007985 & POLR3A & RNA polymerase III subunit A & 008077 & $1.37 \times 10^{-2}$ & 1 & 1 \\
\hline 008005 & PHACTR2 & Phosphatase and actin regulator 2 & 008047 & $3.90 \times 10^{-3}$ & 5 & 1 \\
\hline 008475 & SNTA1 & Syntrophin $\alpha 1$ & 008544 & $5.20 \times 10^{-3}$ & 5 & 1 \\
\hline 008991 & KEAP1 & Kelch-like ECH-associated protein 1 & 009010 & $2.00 \times 10^{-4}$ & 3 & 1 \\
\hline 009213 & SWAP70 & Switching B cell complex subunit SWAP70 & 009242 & $8.70 \times 10^{-3}$ & 1 & 1 \\
\hline 013059 & JPH1 & Junctophilin 1 & 013093 & $1.09 \times 10^{-2}$ & 4 & 1 \\
\hline 013301 & COL1A2 & Collagen type I $\alpha 2$ chain & 013614 & $1.10 \times 10^{-3}$ & 17 & 3 \\
\hline 013326 & ADGRF5 & Adhesion $\mathrm{G}$ protein-coupled receptor F5 & 013405 & $4.00 \times 10^{-4}$ & 1 & 1 \\
\hline 015062 & COL3A1 & Collagen type III $\alpha 1$ chain & 015539 & $3.00 \times 10^{-2}$ & 11 & 4 \\
\hline 015374 & RANBP17 & RAN binding protein 17 & 015630 & $7.90 \times 10^{-3}$ & 3 & 2 \\
\hline 015422 & BAIAP2 & BAR/IMD-domain-containing adaptor protein 2 & 015540 & $4.96 \times 10^{-2}$ & 2 & 2 \\
\hline 016662 & PGS1 & Phosphatidylglycerophosphate synthase 1 & 016740 & $<0.00 \times 10^{-5}$ & 1 & 1 \\
\hline 017208 & FLOT1 & Flotillin 1 & 017291 & $<0.00 \times 10^{-5}$ & 4 & 2 \\
\hline 017228 & SLC4A1 & $\begin{array}{l}\text { Solute carrier family } 4 \text { member } 1 \text { (Diego blood } \\
\text { group) }\end{array}$ & 017345 & $4.36 \times 10^{-2}$ & 2 & 1 \\
\hline 017316 & РТВР3 & Polypyrimidine tract binding protein 3 & 017407 & $6.00 \times 10^{-4}$ & 2 & 3 \\
\hline 018003 & FGFR1 & Fibroblast growth factor receptor 1 & 018080 & $6.00 \times 10^{-4}$ & 2 & 1 \\
\hline \multicolumn{7}{|c|}{$\underline{2000-3500 \mathrm{~m}}$} \\
\hline Gene ID & Gene & Gene description & Transcript & $\mathrm{B}$ & FB & $\mathrm{aB}$ \\
\hline 000306 & ZNF622 & Zinc finger protein 622 & 000291 & $8.50 \times 10^{-3}$ & 5 & 1 \\
\hline 000907 & MICU1 & Mitochondrial calcium uptake 1 & 000909 & $1.30 \times 10^{-3}$ & 1 & 1 \\
\hline 001396 & ABCC3 & ATP-binding cassette subfamily $\mathrm{C}$ member 3 & 001480 & $<0.00 \times 10^{-5}$ & 1 & 1 \\
\hline 002254 & MIA3 & Melanoma inhibitory activity family member 3 & 002276 & $2.22 \times 10^{-2}$ & 1 & 2 \\
\hline 002779 & $\mathrm{CDH} 1$ & Cadherin 1 & 003031 & $1.50 \times 10^{-3}$ & 1 & 1 \\
\hline 004137 & STARD13 & StAR-related lipid transfer domain containing 13 & 004235 & $2.00 \times 10^{-4}$ & 3 & 1 \\
\hline 005084 & COL1A1 & Collagen type I $\alpha 1$ chain & 005298 & $5.00 \times 10^{-4}$ & 18 & 2 \\
\hline 006739 & RALGAPB & Ral GTPase-activating protein, $\beta$ subunit & 006803 & $9.40 \times 10^{-3}$ & 1 & 1 \\
\hline 006920 & NEO1 & Neogenin 1 & 007074 & $<0.00 \times 10^{-5}$ & 1 & 1 \\
\hline 006926 & CTNND1 & Catenin delta 1 & 007006 & $3.00 \times 10^{-4}$ & 1 & 1 \\
\hline 007694 & ACOX1 & Acyl-CoA oxidase 1 & 007823 & $0.00 \times 10^{0}$ & 8 & 1 \\
\hline 007907 & FLOT2 & Flotillin 2 & 008015 & $0.00 \times 10^{0}$ & 1 & 1 \\
\hline 008206 & ADGRG6 & Adhesion G protein-coupled receptor G6 & 008405 & $1.21 \times 10^{-2}$ & 4 & 1 \\
\hline
\end{tabular}


Table 5. Cont.

\begin{tabular}{|c|c|c|c|c|c|c|}
\hline \multicolumn{2}{|c|}{ Lowland } & \multirow{2}{*}{ Gene Description } & \multirow{2}{*}{ Transcript } & \multirow{2}{*}{ B } & \multirow{2}{*}{ FB } & \multirow[b]{2}{*}{$\mathbf{a B}$} \\
\hline GeneID & Gene & & & & & \\
\hline 009366 & PLEKHG3 & $\begin{array}{c}\text { Pleckstrin homology and RhoGEF domain } \\
\text { containing G3 }\end{array}$ & 026649 & $1.43 \times 10^{-2}$ & 1 & 2 \\
\hline 010640 & MYLK & Myosin light chain kinase & 010735 & $3.00 \times 10^{-4}$ & 2 & 1 \\
\hline 011707 & FYN & FYN proto-oncogene, Src family tyrosine kinase & 011760 & $5.00 \times 10^{-3}$ & 1 & 1 \\
\hline 013938 & SPEG & SPEG complex locus & 023342 & $3.99 \times 10^{-2}$ & 2 & 2 \\
\hline 014232 & RBBP5 & RB binding protein 5 & 014319 & $<0.00 \times 10^{-5}$ & 5 & 2 \\
\hline 014373 & CD82 & Tetraspanin & 014458 & $2.92 \times 10^{-2}$ & 5 & 1 \\
\hline 015062 & COL3A1 & Collagen type III $\alpha 1$ chain & 015539 & $2.92 \times 10^{-2}$ & 11 & 4 \\
\hline 015121 & SLC26A4 & Solute carrier family 26 member 4 & 015204 & $3.02 \times 10^{-2}$ & 2 & 1 \\
\hline 015894 & PNN & Pinin, desmosome associated protein & 015973 & $1.56 \times 10^{-2}$ & 1 & 1 \\
\hline 016077 & & & 016133 & $1.00 \times 10^{-3}$ & 4 & 3 \\
\hline 017036 & NIF3L1 & NGG1 interacting factor 3 like 1 & 017110 & $8.50 \times 10^{-3}$ & 4 & 1 \\
\hline \multicolumn{7}{|c|}{$\underline{3500-4500 \mathrm{~m}}$} \\
\hline GeneID & Gene & Gene description & Transcript & B & FB & $\mathrm{aB}$ \\
\hline 000773 & IL1RAP & Interleukin 1 receptor accessory protein & 000813 & $<0.00 \times 10^{-5}$ & 2 & 5 \\
\hline 001545 & ZCCHC8 & Zinc finger CCHC-type containing 8 & 001573 & $2.78 \times 10^{-2}$ & 1 & 2 \\
\hline 002034 & CCDC138 & Coiled-coil domain containing 138 & 002022 & $4.00 \times 10^{-4}$ & 1 & 1 \\
\hline 003612 & NR3C2 & Nuclear receptor subfamily 3 group C member 2 & 003696 & $4.97 \times 10^{-2}$ & 7 & 1 \\
\hline 004231 & COL6A3 & Collagen type VI $\alpha 3$ chain & 004512 & $<0.00 \times 10^{-5}$ & 6 & 2 \\
\hline 005058 & RPL11 & Ribosomal protein L11 & 005076 & $1.67 \times 10^{-2}$ & 1 & 1 \\
\hline 005562 & PFKM & Phosphofructokinase, muscle & 005957 & $4.83 \times 10^{-2}$ & 3 & 2 \\
\hline 006776 & FUS & FUS RNA-binding protein & 006895 & $6.70 \times 10^{-3}$ & 1 & 1 \\
\hline 006926 & CTNND1 & Catenin delta 1 & 007006 & $3.00 \times 10^{-4}$ & 1 & 1 \\
\hline 007250 & ATP11B & ATPase phospholipid transporting 11B (putative) & 007392 & $1.40 \times 10^{-3}$ & 12 & 1 \\
\hline 007887 & ABHD3 & Abhydrolase domain containing 3, phospholipase & 007896 & $4.00 \times 10^{-3}$ & 2 & 2 \\
\hline 009164 & NADK2 & NAD kinase 2 , mitochondrial & 009211 & $1.18 \times 10^{-2}$ & 1 & 1 \\
\hline 009700 & & & 009686 & $5.50 \times 10^{-3}$ & 1 & 1 \\
\hline 009800 & FLNA & Filamin A & 010200 & $0.00 \times 10^{0}$ & 2 & 2 \\
\hline 011843 & SENP7 & SUMO specific peptidase 7 & 011850 & $1.43 \times 10^{-2}$ & 1 & 1 \\
\hline 013301 & COL1A2 & Collagen type I $\alpha 2$ chain & 013614 & $1.20 \times 10^{-3}$ & 17 & 3 \\
\hline 013313 & AGAP2 & $\begin{array}{l}\text { ArfGAP with GTPase domain, ankyrin repeat, PH } \\
\text { domain } 2\end{array}$ & 013455 & $3.40 \times 10^{-3}$ & 1 & 1 \\
\hline 014695 & RFWD2 & COP1 E3 ubiquitin ligase & 014789 & $1.00 \times 10^{-3}$ & 2 & 2 \\
\hline 014919 & ALDOA & Aldolase, fructose-bisphosphate A & 014984 & $2.99 \times 10^{-2}$ & 2 & 1 \\
\hline 015785 & CDK14 & Cyclin-dependent kinase 14 & 015872 & $6.10 \times 10^{-3}$ & 1 & 1 \\
\hline 016662 & PGS1 & Phosphatidylglycerophosphate synthase 1 & 016740 & $<0.00 \times 10^{-5}$ & 1 & 1 \\
\hline 017054 & NFIX & Nuclear factor I X & 017136 & $9.50 \times 10^{-3}$ & 1 & 1 \\
\hline 017166 & FARSA & Phenylalanyl-tRNA synthetase subunit $\alpha$ & 017239 & $2.58 \times 10^{-2}$ & 1 & 2 \\
\hline 017936 & ATP6V0A1 & ATPase $\mathrm{H}+$ transporting V0 subunit a1 & 018008 & $3.50 \times 10^{-3}$ & 1 & 1 \\
\hline \multicolumn{7}{|c|}{ Frogs and lizards, common genes at similar elevation } \\
\hline Gene ID & Gene & Gene description & Transcript & B & FB & $\mathrm{aB}$ \\
\hline 016662 & PGS1 & Phosphatidylglycerophosphate synthase 1 & 016740 & $<0.00 \times 10^{-5}$ & 1 & 1 \\
\hline
\end{tabular}

\section{Discussion}

This study presents the first transcriptome sequences from different tissues of the Ladakh Ground Skink Asymblepharus ladacensis, a high-altitude reptile species endemic to the Greater Himalayas. We provide high-quality de novo transcript assemblies and wellannotated results, enabling comparisons with transcriptomes of related scincid or higher lizards available at public databases. Although squamate reptiles (lizards and snakes) represent one of the most diverse vertebrate groups with over 10,000 species spanning more than 200 million years of evolution [66], genomic data of squamates are limited and still poorly studied [67]. To our knowledge, no annotated transcriptome has been published for the genus Asymblepharus so far. Although our study is mostly descriptive, it has yielded discoveries with respect to genes known to play roles in the adaptation of vertebrates to high elevations and adds data resources for genomic studies in Himalayan herpetofauna.

Yang et al. [15] used comparative transcriptomic analyses of two closely related lizards, Phrynocephalus przewalskii from low elevations (500-1500 $\mathrm{m}$ a.s.l.) and P. vlangalii from high elevations (2000-4600 $\mathrm{m}$ a.s.l.), to identify candidate genes that are potentially linked to 
adaptation to high elevation environments. In addition, Sun et al. [7] tested amphibian and reptile populations at various altitudes in Tibet, which show parallel evolution. These studies demonstrated convergent and continuous adaptation to high elevations in Anura (Ranidae) and Sauropsida (Agamidae). Genes with related functions, especially DNA repair and energy metabolism, exhibit featured rapid changes and are positively correlated to elevation. These data let us assume that a similar genomic high-elevation selection syndrome might be detectable in Asymblepharus, sampled in $2714 \mathrm{~m}$ a.s.l. (Methods), and with a vertical distribution between $\sim 2500$ and $5500 \mathrm{~m}$ ([26] and references therein).

Indeed, we identified a total of 10 out of 143 and 104 out of $\sim 1500$ key genes $[7,15]$ under positive selection in the Asymblepharus transcriptome. Interestingly, several of the 10 genes (Table 4 ) have been reported to be under positive selection or significantly enriched or differentially methylated for pathways consistent with physiological compensation for limited oxygen in high elevation dwellers, e.g., IL1RAP [68] (human), MIA3 [69] (pika), and MICU1 [70] (Ladakhi cow). Several genes we identified to be under positive selection have GO terms that suggest their involvement in, e.g., energy metabolism and DNA repair. It is well-known that high UV radiation and hypoxia are major challenges for organisms in high-altitude habitats. The extreme environments in the Greater Himalayas necessitate high energy metabolism, strong resistance to UV by an efficient DNA repair, and adaptation to hypoxia in species endemic to these mountains. However, the proportion of genes we found in Asymblepharus per 'altitude-specific' gene group does not appear to reflect a convergently evolved gene set as previously reported [7]. In other words, we found a comparable number of genes under positive selection from the group of genes identified for lowland species and those identified for colline, montane, or alpine species. Given the idea of convergent evolutionary changes and, thus, a gradual accumulation of high-elevation genetic adaptations, a higher number of candidate genes reported for montane and alpine species would have been expected in Asymblepharus compared to those genes reported in species distributed in lower elevations. The potential reasons for this supposed lack of confirmation of the suggested pattern are complex. A major limitation is that our analyses were restricted so far to a single Asymblepharus transcriptome. Due to limitations of sampling, data were unobtainable from radiation of species or an altitudinal gradient as available for frogs and other lizards [7,15], preventing us from intraspecific comparisons. Moreover, data of a single specimen cannot reflect the breadth of allelic diversity in the selected genes, putatively associated with adaptations to high altitude, especially in the view of wide vertical distribution. Another deficiency results from the fact that only one female but no male could be sequenced. Indeed, many genes that might be sex-specifically expressed might not have been sequenced or characterized with our approach. Therefore, future research with multiple high-elevation species and populations across a larger scale of altitudinal variation should validate genes known to contribute to high elevation adaptation in scincid reptiles and, thus, yield additional evidence for potential convergent evolution.

A promising future genomic approach might be to include populations of Asymblepharus between the species' lower and upper distributional periphery, sampling three populations at each of four elevation levels (e.g., $<2000 \mathrm{~m}, 3000 \mathrm{~m}, 4000 \mathrm{~m}$, and $5000 \mathrm{~m}$ a.s.l.), to investigate the expression of genes presumably related to adaptions to high altitude. It would also be desirable to reveal potential tissue-specific expression patterns across altitude-associated genes, samples of organs sensitive to UV radiation, and for oxygen, e.g., heart, lung, skin, and embryonic structures, which are particularly of interest. Moreover, to address adaptive convergence, additional comparative transcriptomic analyses on Japalura or Laudakia species might be promising since these taxa have a similarly broad vertical distribution as Asymblepharus and often co-occur with sympatric ground skinks. Asymblepharus might even become an excellent model to study local adaptation by reciprocal transplantation experiments between high and low altitude populations. Such studies could enhance our understanding of how organisms might cope with rapid environmental changes in fluctuating demographic contexts. However, such intensive field studies require 
adequate access to suitable habitats in the Himalayas and, thus, a much higher logistic and financial effort than available in our pilot study.

\section{Conclusions}

In summary, our present study provides the first transcriptomic data for a Himalayan reptile of the genus Asymblepharus and evidence for genes under positive selection for highaltitude adaptation of the Ladakh Ground Skink. Further research is encouraged to validate the key genes confirmed in this study by population genetic and functional genomic approaches. Comparative sequencing analyses for other Asymblepharus species may enable further insights into the adaptive basis of reptiles to different altitude environments in the Himalayas. Our data are available for future investigations on the evolution and environmental adaptation in Himalayan high-altitude vertebrates.

Supplementary Materials: The following are available online at https:/ / www.mdpi.com/article/ 10.3390/genes12091423/s1, Figure S1: Basic statistics for the data derived from brain, embryonic disc, and pooled tissues based on the rnaQUAST report, Table S1: TransRate results for Asymblepharus ladacensis ORP assemblies, Table S2: Results of the quality assessment of the transcriptome assemblies from brain tissue, an embryonic disc, and pooled tissues of Asymblepharus ladacensis using rnaQUAST and the reference database of (a) Anolis carolinensis, (b) Gekko japonicus, and (c) Python bivittatus, Table S3: List of positively selected genes in Phrynocephalus species (according to [2]) and Asymblepharus ladacensis, their functional categories and summary of tests for positive selection.

Author Contributions: Conceptualization, S.H., C.B.B., and M.S.; methodology, S.H., C.B.B., M.S., and L.P.; formal analysis, S.H. and L.P.; investigation, S.H.; resources, S.H., C.B.B., M.S., and L.P.; data curation, S.H.; writing—original draft preparation, S.H.; writing—review and editing, all authors; visualization, S.H.; project administration, S.H.; funding acquisition, S.H. and M.S. All authors have read and agreed to the published version of the manuscript.

Funding: This research was funded by the German Research Foundation, grant number HO 3792/8-1, to S.H., and by COFASP/ERANET (STURGEoNOMICS) by the German Federal Ministry of Food and Agriculture through the Federal Office for Agriculture and Food, grant no. 2816ERA04G, to MS.

Institutional Review Board Statement: All treatments were carried out in accordance with approved guidelines and according to the permit as well as the local animal welfare committee's in-structions (VNME 17, 15-30).

Informed Consent Statement: Not applicable.

Data Availability Statement: Data generated in this study are publicly available from the NCBI GenBank database under the Bioproject ID PRJNA750278, BioSamples SAMN20458631, SAMN20458632, and SAMN20458631. All sequence data were deposited in the NCBI Sequence Read Archive (SRA, http:/ / www.ncbi.nlm.nih.gov/Traces/sra/; accessed on 2 August 2021) under the accession numbers SRR15283177, SRR15283178, and SRR15283179; assembled sequences were transmitted to NCBI Transcriptome Shotgun Assembly Sequence Database (TSA, http:/ /www.ncbi.nlm.nih.gov/genbank/tsa (accessed on 2 August 2021).

Acknowledgments: We are grateful to Markus Sandner and Santos Tamang for their assistance during fieldwork.

Conflicts of Interest: The authors declare no conflict of interest. The funders had no role in the design of the study; in the collection, analyses, or interpretation of data; in the writing of the manuscript, or in the decision to publish the results.

\section{References}

1. Mittermeier, R.A.; Robles-Gil, P.; Homan, M.; Pilgrim, J.; Brooks, T.; Mittermeier, C.G.; Lamoreux, J.; da Fonseca, G.A.B. Hotspots Revisited; CEMEX: Mexico City, Mexico, 2004; p. 392.

2. Hofmann, S.; Stoeck, M.; Zheng, Y.; Ficetola, F.G.; Li, J.T.; Scheidt, U.; Schmidt, J. Molecular Phylogenies Indicate a Paleo-Tibetan Origin of Himalayan Lazy Toads (Scutiger). Sci. Rep. 2017, 7, 3308. [CrossRef] [PubMed]

3. Yang, W.; Qi, Y.; Fu, J. Genetic signals of high-altitude adaptation in amphibians: A comparative transcriptome analysis. BMC Genet. 2016, 17, 134. [CrossRef] [PubMed] 
4. Wang, G.-D.; Zhang, B.-L.; Zhou, W.-W.; Li, Y.-X.; Jin, J.-Q.; Shao, Y.; Yang, H.-C.; Liu, Y.-H.; Yan, F.; Chen, H.-M.; et al. Selection and Environmental Adaptation Along a Path to Speciation in the Tibetan Frog Nanorana parkeri. Proc. Natl. Acad. Sci. USA 2018, 115, E5056-E5065. [CrossRef]

5. Che, J.; Zhou, W.-W.; Hu, J.-S.; Yan, F.; Papenfuss, T.J.; Wake, D.B.; Zhang, Y.-P. Spiny frogs (Paini) illuminate the history of the Himalayan region and Southeast Asia. Proc. Natl. Acad. Sci. USA 2010, 107, 13765-13770. [CrossRef]

6. Lu, B.; Jin, H.; Fu, J. Molecular convergent and parallel evolution among four high-elevation anuran species from the Tibetan region. BMC Genom. 2020, 21, 839. [CrossRef]

7. Sun, Y.B.; Fu, T.T.; Jin, J.Q.; Murphy, R.W.; Hillis, D.M.; Zhang, Y.P.; Che, J. Species Groups Distributed across Elevational Gradients Reveal Convergent and Continuous Genetic Adaptation to High Elevations. Proc. Natl. Acad. Sci. USA 2018, 115, E10634-E10641. [CrossRef]

8. Dorge, T.; Hofmann, S.; Wangdwei, M.; Duoje, L.; Solhøy, T.; Miehe, G. The ecological specialist, Thermophis baileyi (Wall, 1907)—New records, distribution, and biogeographic conclusions. Herpetol. Bull. 2007, 101, 8-12.

9. Jin, Y.T.; Brandt, D.Y.C.; Li, J.; Wo, Y.; Tong, H.; Shchur, V. Elevation as a selective force on mitochondrial respiratory chain complexes of the Phrynocephalus lizards in the Tibetan plateau. Curr. Zool. 2020, 67, 191-199. [CrossRef]

10. Baig, K.J.; Wagner, P.; Ananjeva, N.B.; Böhme, W. A morphology-based taxonomic revision of Laudakia Gray, 1845 (Squamata: Agamidae). Vertebr. Zool. 2012, 62, 213-260.

11. Gangloff, E.J.; Telemeco, R.S. High Temperature, Oxygen, and Performance: Insights from Reptiles and Amphibians. Integr. Comp. Biol. 2018, 58, 9-24. [CrossRef] [PubMed]

12. Jackson, D.C. Temperature and hypoxia in ectothermic tetrapods. J. Thermal. Biol. 2007, 32, 125-133. [CrossRef]

13. Yang, W.J.; Qi, Y.; Bi, K.; Fu, J. Toward Understanding the Genetic Basis of Adaption to High-Elevation Life in Poikilothermic Species: A Comparative Transcriptomic Analysis of Two Ranid Frogs, Rana chensinensis and R. kukunoris. BMC Genom. 2012, 13, 588. [CrossRef]

14. Li, J.T.; Gao, Y.-D.; Xie, L.; Deng, C.; Shi, P.; Guan, M.-L.; Huang, S.; Ren, J.-L.; Wu, D.-D.; Ding, L.; et al. Comparative genomic investigation of high-elevation adaptation in ectothermic snakes. Proc. Natl. Acad. Sci. USA 2018, 115, 8406-8411. [CrossRef] [PubMed]

15. Yang, W.; Qi, Y.; Fu, J. Exploring the genetic basis of adaptation to high elevations in reptiles: A comparative transcriptome analysis of two toad-headed agamas (genus Phrynocephalus). PLoS ONE 2014, 9, e112218. [CrossRef]

16. Hofmann, S.; Kuhl, H.; Baniya, C.B.; Stock, M. Multi-Tissue Transcriptomes Yield Information on High-Altitude Adaptation and Sex-Determination in Scutiger cf. sikimmensis. Genes 2019, 10, 873. [CrossRef] [PubMed]

17. Mosbrugger, V.; Favre, L.; Müllner-Riehl, A.; Päckert, M.; Mulch, A. Cenozoic Evolution of Geo-Biodiversity in the TibetoHimalayan Region. In Mountains, Climate and Biodiversity; Hoorn, C., Perrigo, A., Antonelli, A., Eds.; Wiley-Blackwell: Oxford, UK, 2018; pp. 429-449.

18. Pacifici, M.; Foden, W.B.; Visconti, P.; Watson, J.E.M.; Butchart, S.H.M.; Kovacs, K.M.; Scheffers, B.R.; Hole, D.G.; Martin, T.G.; Akçakaya, H.R.; et al. Assessing species vulnerability to climate change. Nat. Clim. Chang. 2015, 5, 215-225. [CrossRef]

19. Xu, J.; Badola, R.; Chettri, N.; Chaudhary, R.P.; Zomer, R.; Pokhrel, B.; Hussain, S.A.; Pradhan, S.; Pradhan, R. Sustaining Biodiversity and Ecosystem Services in the Hindu Kush Himalaya. In The Hindu Kush Himalaya Assessment; Wester, P., Mishra, A., Mukherji, A., Shrestha, A., Eds.; Springer: Berlin/Heidelberg, Germany, 2019; pp. 127-165.

20. Kouyoumdjian, L.; Gangloff, E.; Souchet, J.; Cordero, G.A.; Dupoué, A.; Aubret, F. Transplanting gravid lizards to high elevation alters maternal and embryonic oxygen physiology, but not reproductive success or hatchling phenotype. J. Exp. Biol. 2019, 222, jeb206839. [CrossRef]

21. Banasiak, K.J.; Xia, Y.; Haddad, G.G. Mechanisms underlying hypoxia-induced neuronal apoptosis. Prog. Neurobiol. 2000, 62, 215-249. [CrossRef]

22. Bickler, P.E.; Donohoe, P.H. Adaptive responses of vertebrate neurons to hypoxia. J. Exp. Biol. 2002, 205, 3579-3586. [CrossRef] [PubMed]

23. Pyron, R.A.; Burbrink, F.T.; Wiens, J.J. A phylogeny and revised classification of Squamata, including 4161 species of lizards and snakes. BMC Evol. Biol. 2013, 13, 93. [CrossRef]

24. Linkem, C.W.; Diesmos, A.C.; Brown, R.M. Molecular systematics of the Philippine forest skinks (Squamata: Scincidae: Sphenomorphus): Testing morphological hypotheses of interspecific relationships. Zool. J. Linn. Soc. Lond. 2011, 163, $1217-1243$. [CrossRef]

25. Shea, G.M.; Greer, A.E. From Sphenomorphus to Lipinia: Generic reassignment of two poorly known New Guinea skinks. J. Herpetol. 2002, 36, 148-156. [CrossRef]

26. Borkin, L.J.; Litvinchuk, S.N.; Melnikov, D.A.; Skorinov, D.V. Altitudinal distribution of skinks of the genus Asymblepharus in the Western Himalaya, India (Reptilia: Sauria: Scincidae). In Biodiversität und Naturausstattung im Himalaya VI; Hartmann, R., Weipert, J., Barclay, M., Eds.; Verein der Freunde \& Förderer des Naturkundemuseums Erfurt e.V.: Erfurt, Germany, 2018 ; pp. $163-167$.

27. Hartmann, M.; Weipert, J.; Weigel, A. Die zoologischen Nepal-Expeditionen des Naturkundemuseums Erfurt. Veröffentlichungen des Nat. Erf. 1998, 17, 15-30.

28. Hartmann, M.; Weipert, J. Biodiversität und Naturausstattung im Himalaya V; Verein der Freunde und Förderer des Naturkundemuseums Erfurt e.V.: Erfurt, Germany, 2015; p. 580. 
29. Andrews, S. FastQC: A Quality Control Tool for High Throughput Sequence Data. 2010. Available online: http://www. bioinformatics.babraham.ac.uk/projects/fastqc/ (accessed on 2 July 2021).

30. Kopylova, E.; Noe, L.; Touzet, H. SortMeRNA: Fast and accurate filtering of ribosomal RNAs in metatranscriptomic data. Bioinformatics 2012, 28, 3211-3217. [CrossRef] [PubMed]

31. Mac Manes, M.D. The Oyster River Protocol: A multi assembler and Kmer approach for de novo transcriptome assembly. PEERJ 2018, 6, e5428. [CrossRef]

32. Hoelzer, M.; Marz, M. De novo transcriptome assembly: A comprehensive cross-species comparison of short-read RNA-Seq assemblers. Gigascience 2019, 8, 1-16.

33. Lu, B.; Zeng, Z.; Shi, T. Comparative study of de novo assembly and genome-guided assembly strategies for transcriptome reconstruction based on RNA-Seq. Sci. China Life Sci. 2013, 56, 143-155. [CrossRef]

34. Bolger, A.M.; Lohse, M.; Usadel, B. Trimmomatic: A flexible trimmer for Illumina sequence data. Bioinformatics 2014, 30, 2114-2120. [CrossRef] [PubMed]

35. Song, L.; Florea, L. Rcorrector: Efficient and accurate error correction for Illumina RNA-seq reads. Gigascience 2015, 4, 48. [CrossRef]

36. Haas, B.; Papanicolaou, A.; Yassour, M.; Grabherr, M.; Blood, P.; Bowden, J.; Couger, M.; Eccles, D.; Li, B.; Lieber, M.; et al. De novo transcript sequence reconstruction from RNA-seq using the Trinity platform for reference generation and analysis. Nat. Protoc. 2013, 8, 1494-1512. [CrossRef]

37. Chikhi, R.; Medvedev, P. Informed and automated k-mer size selection for genome assembly. Bioinformatics 2014, $30,31-37$. [CrossRef]

38. Kannan, S.; Hui, J.; Mazooji, K.; Pachter, L.; Tse, D. Shannon: An Information-Optimal de novo RNA-Seq Assembler. BioRxiv 2016. [CrossRef]

39. Smith-Unna, R.; Boursnell, C.; Patro, R.; Hibberd, J.M.; Kelly, S. TransRate: Reference-free quality assessment of de novo transcriptome assemblies. Genome Res. 2016, 26, 1134-1144. [CrossRef] [PubMed]

40. Seppey, M.; Manni, M.; Zdobnov, E.M. BUSCO: Assessing Genome Assembly and Annotation Completeness. In Gene Prediction. Methods in Molecular Biology; Kollmar, M., Ed.; Humana: Louisville, KY, USA, 2019; Volume 1962.

41. Simao, F.A.; Waterhouse, R.M.; Ioannidis, P.; Kriventseva, E.V.; Zdobnov, E.M. BUSCO: Assessing genome assembly and annotation completeness with single-copy orthologs. Bioinformatics 2015, 31, 3210-3212. [CrossRef]

42. Bushmanova, E.; Antipov, D.; Lapidus, A.; Suvorov, V.; Prjibelski, A.D. rnaQUAST: A quality assessment tool for de novo transcriptome assemblies. Bioinformatics 2016, 32, 2210-2212. [CrossRef] [PubMed]

43. Buchfink, B.; Xie, C.; Huson, D.H. Fast and sensitive protein alignment using DIAMOND. Nat. Methods 2015, 12, 59-60. [CrossRef]

44. Altschul, S.F.; Gish, W.; Miller, W.; Myers, E.W.; Lipman, D.J. Basic Local Aligment Search Tool. J. Mol. Biol. 1990, $215,403-410$. [CrossRef]

45. Conesa, A.; Gotz, S. Blast2GO: A comprehensive suite for functional analysis in plant genomics. Int. J. Plant Genom. 2008, 2008, 619832. [CrossRef]

46. Quevillon, E.; Silventoinen, V.; Pillai, S.; Harte, N.; Mulder, N.; Apweiler, R.; Lopez, R. InterProScan: Protein domains identifier. Nucleic Acids Res. 2005, 33, W116-W120. [CrossRef] [PubMed]

47. Mistry, J.; Finn, R.D.; Eddy, S.R.; Bateman, A.; Punta, M. Challenges in homology search: HMMER3 and convergent evolution of coiled-coil regions. Nucleic Acids Res. 2013, 41, e121. [CrossRef] [PubMed]

48. Rice, P.; Longden, I.; Bleasby, A. EMBOSS: The European Molecular Biology Open Software Suite. Trends Genet. 2000, 16, $276-277$. [CrossRef]

49. Litvinchuk, S.N.; Borkin, L.J.; Hofmann, S. Rediscovery of the high-altitude Lazy Toad, Scutiger occidentalis Dubois, 1978, in India. Russ. J. Herpetol. 2019, 26, 17-22. [CrossRef]

50. Katoh, K.; Standley, D.M. MAFFT multiple sequence alignment software version 7: Improvements in performance and usability. Mol. Biol. Evol. 2013, 30, 772-780. [CrossRef]

51. Price, M.N.; Dehal, P.S.; Arkin, A.P. FastTree 2-Approximately maximum-likelihood trees for large alignments. PLoS ONE 2010, 5, e9490. [CrossRef]

52. Kosakovsky Pond, S.L.; Poon, A.F.Y.; Velazquez, R.; Weaver, S.; Hepler, N.L.; Murrell, B.; Shank, S.D.; Magalis, B.R.; Bouvier, D.; Nekrutenko, A.; et al. HyPhy 2.5-A Customizable Platform for Evolutionary Hypothesis Testing Using Phylogenies. Mol. Biol. Evol. 2020, 37, 295-299. [CrossRef]

53. Pond, S.L.; Frost, S.D.; Muse, S.V. HyPhy: Hypothesis testing using phylogenies. Bioinformatics 2005, 21, 676-679. [CrossRef] [PubMed]

54. Spielman, S.J.; Weaver, S.; Shank, S.D.; Magalis, B.R.; Li, M.; Kosakovsky Pond, S.L. Evolution of Viral Genomes: Interplay Between Selection, Recombination, and Other Forces. In Evolutionary Genomics. Methods in Molecular Biology; Anisimova, M., Ed.; Humana: Louisville, KY, USA, 2019; Volume 1910.

55. Murrell, B.; Weaver, S.; Smith, M.D.; Wertheim, J.O.; Murrell, S.; Aylward, A.; Eren, K.; Pollner, T.; Martin, D.P.; Smith, D.M.; et al. Gene-wide identification of episodic selection. Mol. Biol. Evol. 2015, 32, 1365-1371. [CrossRef]

56. Murrell, B.; Moola, S.; Mabona, A.; Weighill, T.; Sheward, D.; Kosakovsky Pond, S.L.; Scheffler, K. FUBAR: A fast, unconstrained Bayesian approximation for inferring selection. Mol. Biol. Evol. 2013, 30, 1196-1205. [CrossRef] 
57. Smith, M.D.; Wertheim, J.O.; Weaver, S.; Murrell, B.; Scheffler, K.; Pond, S.L.K. Less is more: An adaptive branch-site random effects model for efficient detection of episodic diversifying selection. Mol. Biol. Evol. 2015, 32, 1342-1353. [CrossRef]

58. Kosakovsky, P.S.L.; Murrell, B.; Fourment, M.; Frost, S.D.; Delport, W.; Scheffler, K. 2011 A random effects branch-site model for detecting episodic diversifying selection. Mol. Biol. Evol. 2011, 28, 3033-3043. [CrossRef]

59. Mi, H.; Muruganujan, A.; Thomas, P.D. PANTHER in 2013: Modeling the evolution of gene function, and other gene attributes, in the context of phylogenetic trees. Nucleic Acids Res. 2013, 41, D377-D386. [CrossRef]

60. Moreno-Santillan, D.D.; Machain-Williams, C.; Hernandez-Montes, G.; Ortega, J. De Novo Transcriptome Assembly and Functional Annotation in Five Species of Bats. Sci. Rep. 2019, 9, 6222. [CrossRef] [PubMed]

61. Theissinger, K.; Falckenhayn, C.; Blande, D.; Toljamoc, A.; Gutekunstb, J.; Makkonenc, J.; Jussilac, J.; Lykob, F.; Schrimpfa, A.; Schulza, R.; et al. De novo assembly and annotation of the freshwater crayfish Astacus astacus transcriptome. Mar. Genom. 2016, 28, 7-10. [CrossRef]

62. Waits, D.S.; Simpson, D.Y.; Sparkman, A.M.; Bronikowski, A.M.; Schwartz, T.S. The utility of reptile blood transcriptomes in molecular ecology. Mol. Ecol. Resour. 2020, 20, 308-317. [CrossRef] [PubMed]

63. Carruthers, M.; Yurchenko, A.A.; Augley, J.J.; Adams, C.E.; Herzyk, P.; Elmer, K.R. De novo transcriptome assembly, annotation and comparison of four ecological and evolutionary model salmonid fish species. BMC Genom. 2018, 19, 32.

64. Bushmanova, E.; Antipov, D.; Lapidus, A.; Prjibelski, A.D. rnaSPAdes: A de novo transcriptome assembler and its application to RNA-Seq data. Gigascience 2019, 8, giz100. [CrossRef] [PubMed]

65. Gates, K.; Sandoval-Castillo, J.; Bernatchez, L.; Beheregaray, L.B. De novo transcriptome assembly and annotation for the desert rainbowfish (Melanotaenia splendida tatei) with comparison with candidate genes for future climates. Mar. Genom. 2017, 35, 63-68. [CrossRef]

66. Murphy, W.J.; Pringle, T.H.; Crider, T.A.; Springer, M.S.; Miller, W. Using genomic data to unravel the root of the placental mammal phylogeny. Genome Res. 2007, 17, 413-421. [CrossRef] [PubMed]

67. Pasquesi, G.I.M.; Adams, R.H.; Card, D.C.; Schield, D.R.; Corbin, A.B.; Perry, B.W.; Reyes-Velasco, J.; Ruggiero, R.P.; Vandewege, M.W.; Shortt, J.A.; et al. Squamate reptiles challenge paradigms of genomic repeat element evolution set by birds and mammals. Nat. Commun. 2018, 9, 2774. [CrossRef]

68. Childebayeva, A.; Goodrich, J.M.; Léon-Velarde, F.; Rivera-Chira, M.; Kiyamu, M.; Brutsaert, T.; Dolinoy, D.; Bigham, A. Genomewide DNA methylation changes associated with high-altitude acclimatization during an Everest base camp trek. Front. Physiol. 2021, 12, 660906. [CrossRef]

69. Solari, K.A.; Ramakrishnan, U.; Hadly, E.A. Gene expression is implicated in the ability of pikas to occupy Himalayan elevational gradient. PLoS ONE 2018, 13, e0207936. [CrossRef] [PubMed]

70. Verma, P.; Sharma, A.; Sodhi, M.; Thakur, K.; Kataria, R.; Niranjan, S.K.; Bharti, V.; Kumar, P.; Giri, A.; Kalia, S.; et al. Transcriptome analysis of circulating PBMCs to understand mechanism of high-altitude adaptation in native cattle of Ladakh region. Sci. Rep. 2018, 8, 7681. [CrossRef] [PubMed] 